\title{
Antigen Binding and Site-Directed Labeling of Biosilica-Immobilized Fusion Proteins Expressed in Diatoms
}

\section{SUPPORTING INFORMATION}

\author{
Nicole R. Ford, ${ }^{\dagger}$ Karen A. Hecht, ${ }^{\dagger}$ DeHong Hu, ${ }^{\ddagger}$ Galya Orr, ${ }^{\ddagger}$ Yijia Xiong,${ }^{\S}$ Thomas C. Squier,${ }^{\S}$ \\ Gregory L. Rorrer," and Guritno Roesijadi ${ }^{\dagger} *$ \\ ${ }^{\dagger}$ Marine Biotechnology, Pacific Northwest National Laboratory, Sequim, WA 98382 \\ * Environmental Molecular Sciences Laboratory, Pacific Northwest National Laboratory, \\ Richland, WA 99352 \\ ${ }^{\S}$ Department of Basic Medical Sciences, Western University of Health Sciences, Lebanon, OR \\ 97355 \\ ${ }^{\nabla}$ Department of Microbiology, "School of Chemical, Biological, and Environmental \\ Engineering, Oregon State University, Corvallis, OR 97331
}

*Corresponding author

g.roesijadi@pnnl.gov

\section{- SUPPLEMENTARY METHODS}

Diatom-specific destination vector cloning. To create the diatom-specific destination vector, the $T$. pseudonana $f_{c p}$ terminator was amplified from the $\mathrm{pTpfcp/nat}$ plasmid ${ }^{l}$ using primers encoding flanking SalI restriction sites. This fragment was digested with SalI and cloned back into the $\mathrm{pTpfcp/nat} \mathrm{plasmid} \mathrm{using} \mathrm{the} \mathrm{unique} \mathrm{SalI} \mathrm{restriction} \mathrm{site} \mathrm{upstream} \mathrm{of} \mathrm{the} f c p$ promoter of the nourseothricin (NAT) resistance cassette. Next, a fragment from Invitrogen's pEXP2-DEST Gateway destination vector was amplified from the attR1 site (introducing an ApaI restriction site) through the $6 \mathrm{xHis}$ tag (introducing an XhoI restriction site). This fragment was digested with ApaI and XhoI, and inserted into the unique ApaI and XhoI sites upstream of the SalI restriction site in the modified $\mathrm{pTpfcp/nat} \mathrm{vector} \mathrm{to} \mathrm{create} \mathrm{the} \mathrm{diatom-specific}$ destination vector (pDDV1). Thus, pDDV1 contains the attR1/2 Gateway integration cassette with V5 and 6xHis epitope tags, a static diatom terminator, and the NAT selection cassette. Primers used for PCR amplification are described in Table S1. Both the intermediate clone and final destination vector were verified by DNA sequencing (Genewiz).

Expression clone construction. Invitrogen's Multi-Site Gateway Pro cloning protocol was used to construct entry clones (Tables S2 and S3) and expression clones containing two, three, or four inserts (Table S4) according to manufacturer instructions. All entry and expression clones were verified by DNA sequencing (Genewiz). All diatom expression clones created for this work contain the T. pseudonana constitutive $f c p$ promoter ${ }^{2}$, but other promoters (e.g., the inducible nitrate reductase $[\mathrm{NR}]$ promoter $^{l}$ ) also could be used in the future. All diatom expression clones also contained $\mathrm{Sil}_{\mathrm{T} 8}$ (a truncated version of the T. pseudonana silaffin 3, which has greater silica targeting efficiency than the full-length Sil3 protein ${ }^{3}$ ), but other silica-targeting proteins (e.g., full-length or other truncated silaffins, ${ }^{3}$ or cingulins ${ }^{4}$ ) also could be used in the future. We extended the recombinatorial power of MultiSite Gateway Pro cloning by coupling short tag sequences such as the Cy3TAG, the enterokinase cleavage site, and additional 6xHis epitope tag into the PCR amplification of the entry clone gene fragments where appropriate (Table S2). 
PCR for expression clone integration. To verify integration of Gateway expression clones into the T. pseudonana genome, PCR was performed directly on $5 \mu \mathrm{L}$ diatom culture $(1 / 10$ volume of PCR). Both multiplex and single amplicon PCRs were used to verify genomic integration (Figure S2). Multiplex PCR troubleshooting was performed following established protocols. ${ }^{5}$ Sequences of PCR primers are described in Table S1.

RT-PCR. $2.5-5 \times 10^{8}$ transformed or native T. pseudonana cells were collected in mid-log phase, and frozen at $-80^{\circ} \mathrm{C}$. RNA was isolated from frozen diatom samples using TRI-Reagent (Sigma-Aldrich) following manufacturer specifications, with established modifications for diatoms. ${ }^{6-8}$ Contaminating genomic DNA was removed by using RNase-free DNase digestion and a Plant RNeasy Mini Kit (Qiagen) according to manufacturer instructions. First strand cDNA synthesis was performed using a RevertAid Kit (Thermo-Fisher) according to manufacturer instructions (450 $\mu \mathrm{g}$ RNA, random hexamer primers). cDNAs were diluted 10 -fold, and $2 \mu \mathrm{L}$ of this dilution was used in the PCRs. Sequences of PCR primers are described in Table S1. 


\section{- SUPPLEMENTARY TABLES}

Table S1: PCR primers for cloning and analysis

\begin{tabular}{|c|c|c|c|}
\hline Primer Name & Use $^{\mathrm{a}}$ & Sequence & Location in Gene \\
\hline fcpT_SalI_F & $\mathrm{C}$ & 5'-GGCGAGCAGTCGACCTACATGAGCATGCCCTG-3' & $\begin{array}{l}5^{\prime} \text { terminus of T. pseudonana } f c p \text { terminator in pTpfep/nat, }{ }^{b} \\
\text { introduces a SalI restriction site (underlined) }\end{array}$ \\
\hline fcpT_SalI_R & $\mathrm{C}$ & 5'-CCCTCACTAAAGTCGACAAAAGCTGGAGCTC-3' & $\begin{array}{l}3^{\prime} \text { terminus of } T \cdot \text { pseudonana fcp terminator in pTpfep/nat, } \\
\text { introduces a SalI restriction site (underlined) }\end{array}$ \\
\hline Dest_ApaI_F & $\mathrm{C}$ & 5'-CTTTGGGCCCGAATTATCAACAAGTTTG-3' & $\begin{array}{l}\text { 5' terminus of pEXP2-DEST Gateway insert (attR1 side), } \\
\text { introduces an ApaI restriction site (underlined) }\end{array}$ \\
\hline Dest_XhoI_R & $\mathrm{C}$ & 5'-CCCCTCGAGGTTATGCTAGTTATTGCTCAGC-3' & $\begin{array}{c}\text { 3' terminus of pEXP2-DEST Gateway insert (attR2 side), } \\
\text { introduces an XhoI restriction site (underlined) }\end{array}$ \\
\hline fcpP MP F & I & 5'-GAAGTAACGTATCTTCCCCCTCGACTGGAT-3' & $\sim 200 \mathrm{bp}$ upstream of T. pseudonana fcp promoter $3^{\prime}$ terminus \\
\hline Sil3_MP_R & I & $\begin{array}{l}\text { 5'-CTAGACTCCTTTGAGGCCTTGGCATCG } \\
\end{array}$ & In exon 3 of T. pseudonana sil3 gene (in T8 fragment) \\
\hline TNTscFv_MP_F & I & 5'-GGACCTGGCCTGGTGAAACCTTCTC-3' & 5 ' terminus of $\mathrm{scFv}_{\mathrm{TNT}}$ gene \\
\hline TNTscFv_MP_R & $\mathrm{I}, \mathrm{R}$ & 5'-TGATTGCTGGAGACTGGGTGAGAAC-3' & $\sim 300 \mathrm{bp}$ upstream of $\mathrm{scFv} \mathrm{V}_{\mathrm{TNT}}$ gene 3 ' terminus \\
\hline BA_MP_F & I & 5'-CTGATGTGCAGCTGCAGGCGTCTGG-3' & 5 ' terminus of $\mathrm{sdAb}_{\mathrm{EA} 1}$ gene \\
\hline BA_MP_R & $\mathrm{I}, \mathrm{R}$ & 5'-TGAGGAGACGGTGACCTGGGTCC-3' & 3' terminus of $s d \mathrm{Ab}_{\mathrm{EA} 1}$ gene \\
\hline GFP_MP_F & I & 5'-ACGTAAACGGCCACAAGTTCAGCGT-3' & $\sim 60 \mathrm{bp}$ downstream of EGFP gene 5 ' terminus \\
\hline GFP_MP_R & I & 5'-CGTCCTCCTTGAAGTCGATGCCCTT-3' & $\sim 300$ bp upstream of EGFP gene 3 ' terminus \\
\hline TpGAPDH_MP_F & I & 5'-GGACAAACCGTCACCCACGATAAG-3' & $\begin{array}{c}\sim 300 \text { bp downstream of } T \text {. pseudonana GAPDH gene } 5 \text { ' terminus } \\
\text { (Thaps protein ID: } 257164 \text { ) }\end{array}$ \\
\hline TpGAPDH_MP_R & $\mathrm{I}, \mathrm{R}$ & 5'-TGCGTGCACAGATGGTCTCGTA-3' & $\begin{array}{l}\sim 200 \mathrm{bp} \text { upstream of T. pseudonana GAPDH gene 3' terminus } \\
\text { (Thaps protein ID: 257164) }\end{array}$ \\
\hline TpGAPDH_quantR_F & $\mathrm{R}$ & 5'-CATTGGTCGCCTGGTCATG-3' & $\begin{array}{c}\text { At 3' end of first exon in T. pseudonana GAPDH gene } \\
\text { (Thaps protein ID: 257164) }\end{array}$ \\
\hline Sil3_exp_F & $\mathrm{R}$ & 5'-ATGAAGACTTCTGCCATTGTATTGCTTG-3' & ER signal sequence of $\operatorname{Sil}_{\mathrm{T} 8}$ ( $5^{\prime}$ terminus of coding region) \\
\hline
\end{tabular}

${ }^{\mathrm{a}}: \mathrm{C}=$ diatom destination vector cloning; $\mathrm{I}=$ Integration verification PCR; $\mathrm{R}=$ Reverse transcriptase PCR

${ }^{\mathrm{b}}$ : see Supplemental Reference 1 
Table S2: PCR primers for Gateway entry clones

\begin{tabular}{|c|c|}
\hline Name & Sequence $^{\mathrm{a}}$ \\
\hline fcpP_attB1_F & $\begin{array}{c}\text { 5'-GGGGACAAGTTGTACAAAAAAGCAGGCTCTAGCTTGCGCTTTTTCCGAGA-3' } \\
\text { attB1 } \\
f_{c p} \text { promoter }\end{array}$ \\
\hline fcpP_attB4_R & 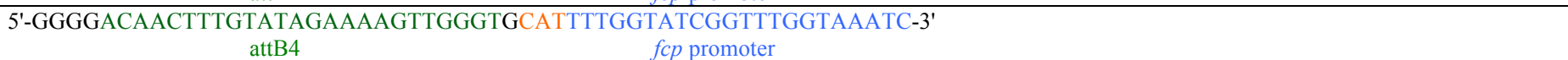 \\
\hline fcpP_attB5r_R & $\begin{array}{c}\text { 5'-GGGGACAACTTTTGTATACAAAGTTGTCATTTTGGTATCGGTTTGGTAAATC-3' }^{\text {attB5r }} \quad f_{c p} \text { promoter } \\
\end{array}$ \\
\hline Sil3T8_attB4r_F & 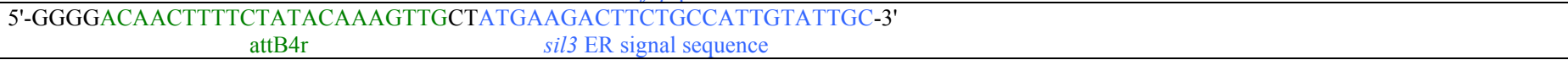 \\
\hline T8_Cy3TAG_attB3r_R & $\begin{array}{c}\text { 5'-GGGGACAACTTTATTATACAAAGTTGTGCAACAGGCAGCCTCAGCCTTACAACAGGCCTCACGAGCTCCACCCTTCCCACTCTTTCCCTTG-3' }^{\text {attB3r }} \text { Cy3TAG } \\
\text { sil }\end{array}$ \\
\hline Sil3T8_attB5_F & 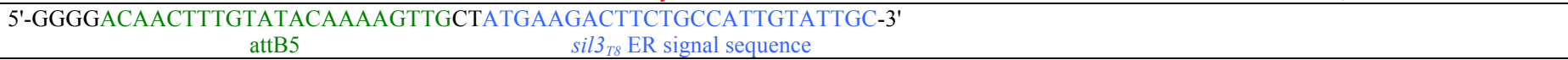 \\
\hline T8_Cy3TAG_attB4_R & $\begin{array}{l}\text { 5'-GGGGACAACTTTGTATAGAAAAGTTGGGTGGCAACAGGCAGCCTCAGCCTTACAACAGGCCTCACGAGCTCCACCCTTCCCACTCTTTCCCTTG-3' }^{\text {attB4 }} \quad \text { Cy3TAG } \\
\end{array}$ \\
\hline EK_EGFP_attB3_F & 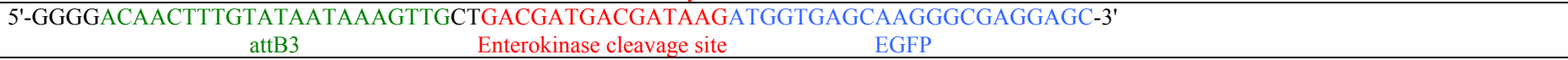 \\
\hline EGFP_His6_attB2_R & 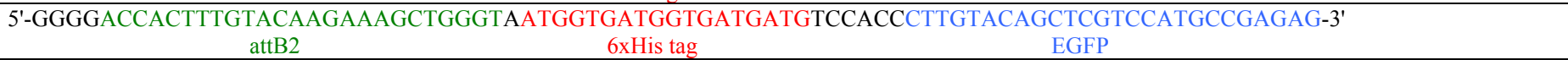 \\
\hline aTNT_attB4r_F & $\begin{array}{l}\text { 5'-GGGGACAACTTTTCTATACAAAGTTGCTGATGTGCAGCTTCAGGAGTCGGG-3' } \\
\qquad \begin{array}{l}\text { attB4r } \\
\operatorname{scFv}_{\text {TNT }}\end{array}\end{array}$ \\
\hline aTNT_attB3r_R & $\begin{array}{c}\begin{array}{c}\text { 5'-GGGGACAACTTTATTATACAAAGTTGTTTTCAGCTCCAGCTTGGTCC-3' } \\
\text { attB3r } \\
\text { scFv }_{\text {TNT }}\end{array} \\
\end{array}$ \\
\hline aTNT_attB3_F & $\begin{array}{l}\text { 5'-GGGGACAACTTTGTATAATAAAGTTGCTGATGTGCAGCTTCAGGAGTCGGG-3' } \\
\text { attB3 } \\
\text { scFv }_{\text {TNT }}\end{array}$ \\
\hline aTNT_attB2_R & $\begin{array}{c}\begin{array}{c}\text { 5'-GGGGACCACTTTGTACAAGAAAGCTGGGTATTTCAGCTCCAGCTTGGTCC-3' } \\
\text { attB2 } \\
\text { scFv }_{\text {TNT }}\end{array} \\
\end{array}$ \\
\hline BA_attB4r_F & $\begin{array}{l}\begin{array}{c}\text { 5'-GGGGACAACTTTTCTATACAAAGTTGCTGATGTGCAGCTGCAGGCGTCTGG-3' } \\
\text { attB4r } \\
\text { sdAb }_{\text {EAl }}\end{array} \\
\end{array}$ \\
\hline BA_attB3r_R & $\begin{array}{c}\text { 5'-GGGGACAACTTTATTATACAAAGTTGTTGAGGAGACGGTGACCTGGGTCC-3' } \\
\text { attB3r } \\
\text { sdAb }\end{array}$ \\
\hline BA_attB3_F & $\begin{array}{l}\text { 5'-GGGGACAACTTTGTATAATAAAGTTGCTGATGTGCAGCTGCAGGCGTCTGG-3' } \\
\text { attB3 } \\
\text { sdAb }\end{array}$ \\
\hline BA_attB2_R & $\begin{array}{l}\text { 5'-GGGGACCACTTTGTACAAGAAAGCTGGGTATGAGGAGACGGTGACCTGGGTCC-3' } \\
\text { attB2 } \\
\text { sdAb }_{\text {EA1 }}\end{array}$ \\
\hline EA1_attB1_F & $\begin{array}{c}\text { 5'-GGGGACAAGTTGTACAAAAAAGCAGGCTCTAGCTTATGGGTAAAAGCTTTCCGGA-3' } \\
\text { attB1 } \\
\text { eag (optimized for } E \text {. coli) }\end{array}$ \\
\hline EA1_attB5r_R & $\begin{array}{l}\text { 5'-GGGGACAACTTTTGTATACAAAGTTGTCAGGTTAGGATTATTTAAAACG-3' }^{\text {attB5r }} \quad \text { eag (optimized for } E \text {. coli) } \\
\end{array}$ \\
\hline EK_EGFP_attB5_F & 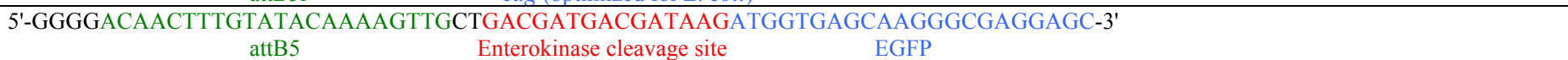 \\
\hline
\end{tabular}

: Important features are highlighted (green = attB site; blue = amplicon sequence; red = binding/cleavage sites) and annotated as to their identity.

b: The $f_{c p}$ promoter is amplified in its entirety, ${ }^{l}$ and includes an ATG start site (orange). 
Table S3: Gateway entry clones created

\begin{tabular}{|c|c|c|c|c|c|}
\hline Entry Clone Name & pDONR & Forward Primer & Reverse Primer & PCR Template & Reference $^{\mathrm{a}}$ \\
\hline pENTR1/4-fcpP & pDONR221 P1-P4 & fcpP_attB1_F & fcpP_attB4_R & $\mathrm{pTpfcp/nat}$ & 1 \\
\hline pENTR1/5r-fcpP & pDONR221 P1-P5r & fcpP_attB1_F & fcpP_attB5r_R & $\mathrm{pTpfcp/nat}$ & $T$ \\
\hline pENTR4r/3r-Sil3 ${ }_{\mathrm{T} 8}-\mathrm{Cy} 3 \mathrm{TAG}$ & pDONR221 P4r-P3r & Sil3T8_attB4r_F & T8_attB3r_R & pTpfcp/T8-GFP/fcp/nat & 3 \\
\hline pENTR5/4-Sil3 ${ }_{\mathrm{T} 8}-\mathrm{Cy} 3 \mathrm{TAG}$ & pDONR221 P5-P4 & Sil3T8_attB5_F & T8_attB4_R & pTpfcp/T8-GFP/fcp/nat & 3 \\
\hline pENTR3/2-EK-EGFP & pDONR221 P3-P2 & EK_EGFP_attB3_F & EGFP_His6_attB2_R & pTpfcp/T8-GFP/fcp/nat & 3 \\
\hline pENTR4r/3r-scFv $v_{\text {TNT }}$ & pDONR221 P4r-P3r & aTNT_attB4r_F & aTNT_attB3r_R & pET22B(+)- $\alpha \mathrm{TNT}$ scFv & 9 \\
\hline pENTR3/2-scFv $v_{\text {TNT }}$ & pDONR221 P5-P4 & aTNT_attB3_F & aTNT_attB2_R & pET22B(+)- $\alpha$ TNT scFv & 9 \\
\hline pENTR4r/3r-scFv $v_{\text {EA1 }}$ & pDONR221 P4r-P3r & BA_attB4r_F & BA_attB3r_R & pET22B(+)-BA A1 & 10 \\
\hline pENTR3/2-scFv $v_{\text {EA1 }}$ & pDONR221 P5-P4 & BA_attB3_F & BA_attB2_R & $\mathrm{pET} 22 \mathrm{~B}(+)-\mathrm{BA} \mathrm{A} 1$ & 10 \\
\hline pENTR1/5r-EA1 & pDONR221 P1-P5r & EA1_attB1_F & EA1_attB5r_R & pUC57-eag & This study \\
\hline pENTR5/2-EK-EGFP & pDONR221 P5-P2 & EK_EGFP_attB5_F & EGFP_His6_attB2_R & pUC57-eag & This study \\
\hline
\end{tabular}

${ }^{\mathrm{a}}$ : Reference for PCR template

Table S4: Gateway expression clones created

\begin{tabular}{|c|c|c|c|c|c|}
\hline Expression Clone Name & Destination Vector & Entry Clone 1 & Entry Clone 2 & Entry Clone 3 & Entry Clone 4 \\
\hline DDV1-f/T8CEKG & pDDV1 & pENTR1/4-fcpP & pENTR4r/3r-Sil3 ${ }_{\mathrm{T} 8}-\mathrm{Cy} 3 \mathrm{TAG}$ & pENTR3/2-EK-EGFP & - \\
\hline DDV1-f/T8CTEKG & pDDV1 & pENTR1/5r-fcpP & pENTR5/4-Sil3 ${ }_{\mathrm{T} 8}-\mathrm{Cy} 3 \mathrm{TAG}$ & pENTR4r/3r- $\alpha$ TNT scFv & pENTR3/2-EK-EGFP \\
\hline DDV1-f/T8CT & pDDV1 & pENTR1/4-fcpP & $\mathrm{pENTR} 4 \mathrm{r} / 3 \mathrm{r}-\mathrm{Sil} 3_{\mathrm{T} 8}-\mathrm{Cy} 3 \mathrm{TAG}$ & pENTR3/2- $\alpha$ TNT scFv & - \\
\hline DDV1-f/T8CA1EKG & pDDV1 & pENTR1/5r-fcpP & pENTR5/4-Sil3 ${ }_{\mathrm{T} 8}-\mathrm{Cy} 3 \mathrm{TAG}$ & $\mathrm{pENTR} 4 \mathrm{r} / 3 \mathrm{r}-\alpha \mathrm{EA} 1 \mathrm{sdAb}$ & pENTR3/2-EK-EGFP \\
\hline DDV1-f/T8CA1 & pDDV1 & pENTR1/4-fcpP & $\mathrm{pENTR} 4 \mathrm{r} / 3 \mathrm{r}-\mathrm{Sil3}{ }_{\mathrm{T} 8}-\mathrm{Cy} 3 \mathrm{TAG}$ & pENTR3/2- $\alpha$ EA1 sdAb & - \\
\hline pEXP2-EA1-GFP & pEXP2-DEST & pENTR1/5r-EA1 & pENTR5/2-EK-EGFP & - & - \\
\hline
\end{tabular}


- SUPPLEMENTARY FIGURES

a. Multi-Site Gateway Pro recombination reaction

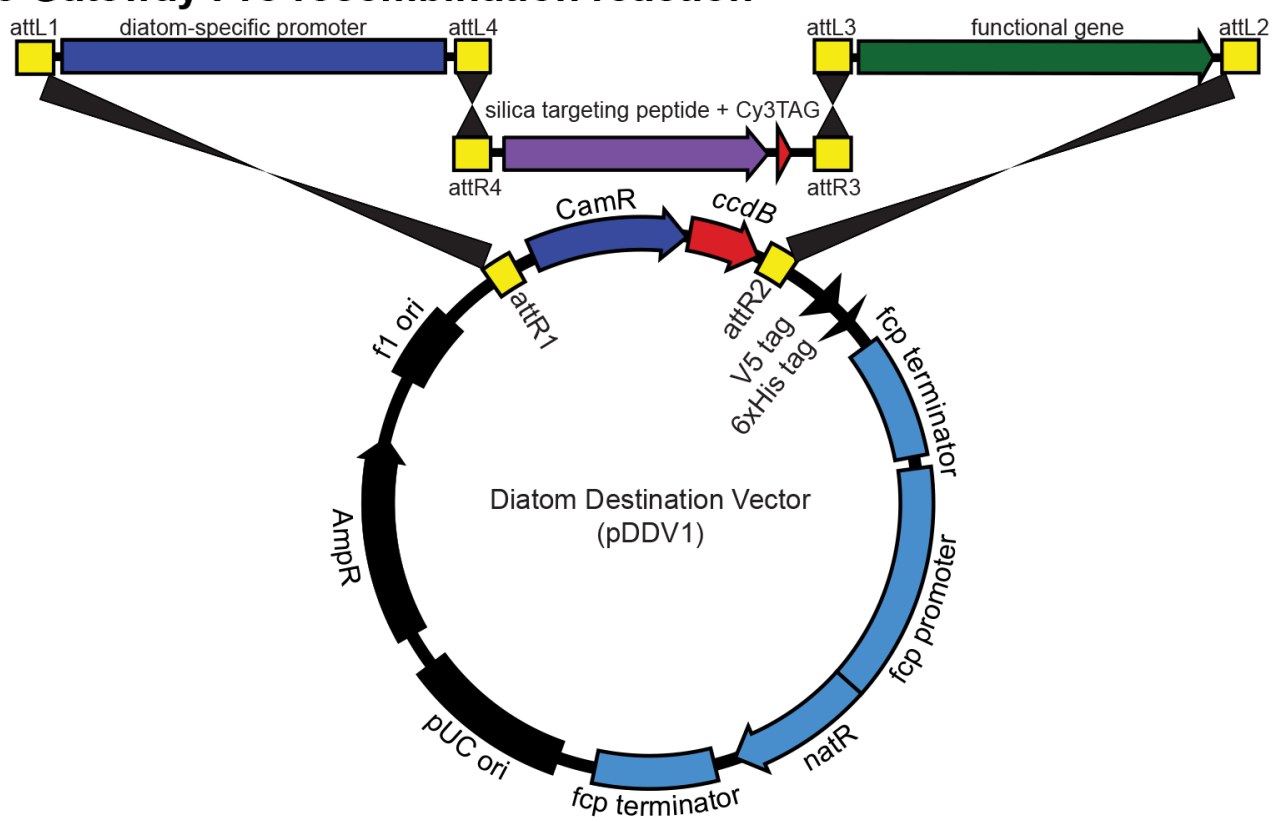

\section{b. Gateway expression clone}
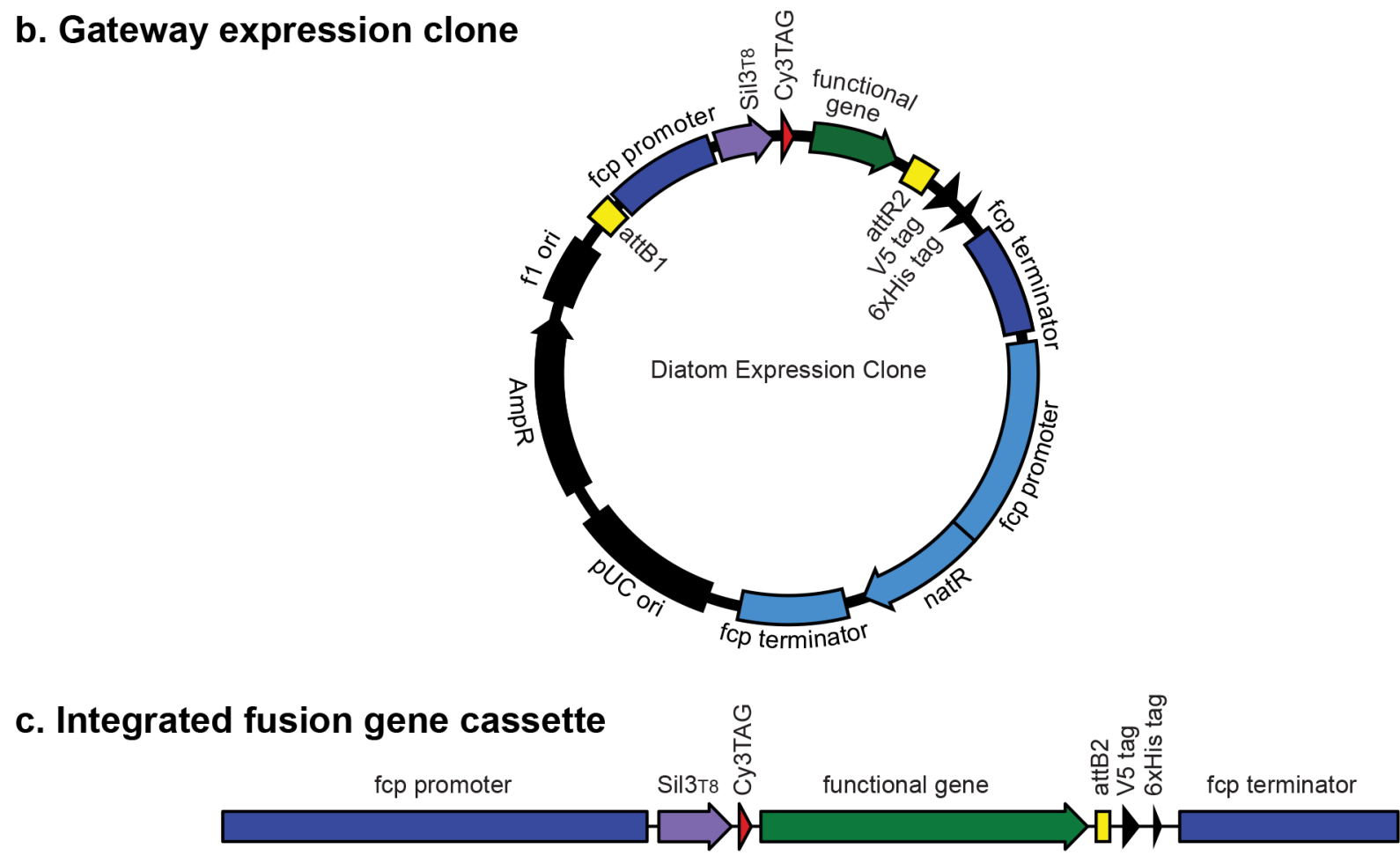

Figure S1. Diatom expression clone construction. a. Recombination reactions between entry clones and diatom-specific Gateway destination vector pDDV1. b. Resultant generic expression clone for transformation of $T$. pseudonana. c. Linear depiction of the fusion gene integrated into the diatom genome. 


\section{a. Multiplex PCR with EGFP-tagged scFv $\mathbf{T N T}_{\mathrm{TN}}$-transformed diatoms}

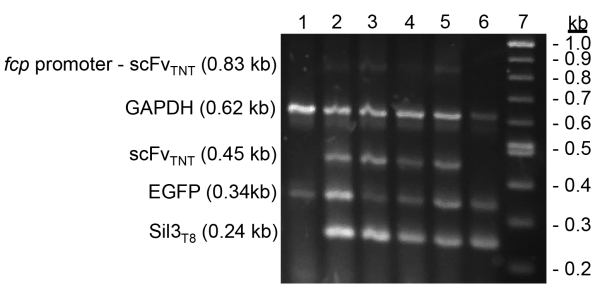

\section{c. Multiplex PCR with scFv TNT- $^{-}$ transformed diatoms}

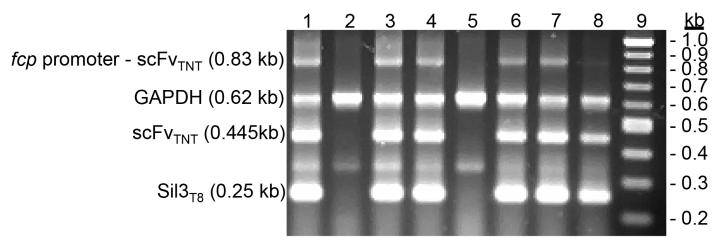

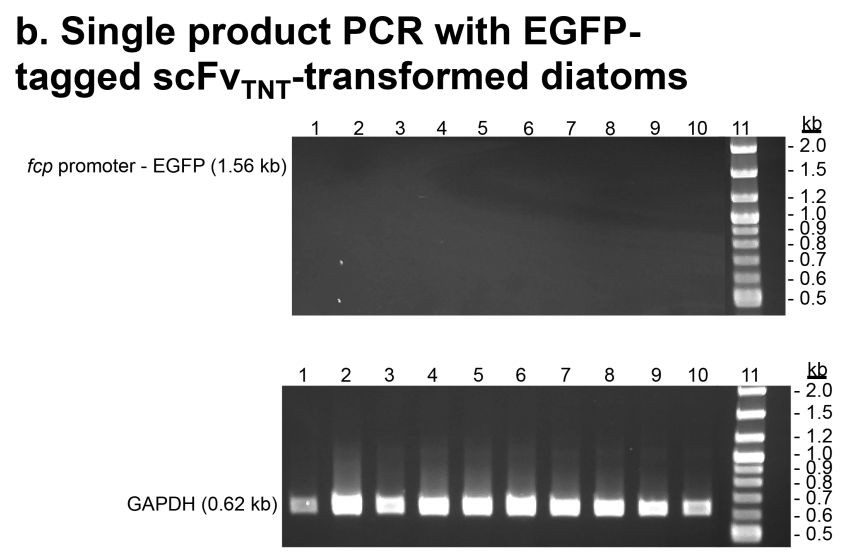

\section{d. Single product PCR with scFv $_{\mathrm{TNT}^{-}}$ transformed diatoms}
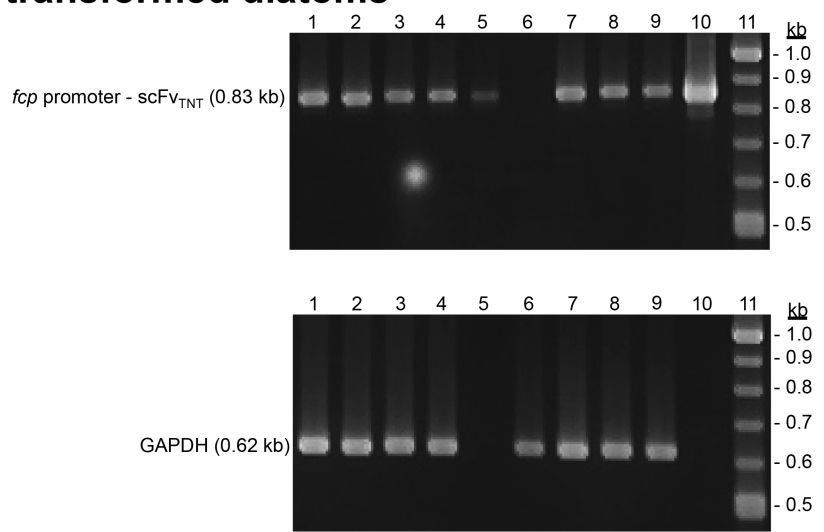

Figure S2. Integration of $\mathrm{scFv}_{\mathrm{TNT}}$-containing fusion genes into the $\boldsymbol{T}$. pseudonana genome. Four-insert Sil3 ${ }_{\mathrm{T} 8}-\mathrm{Cy} 3 \mathrm{TAG}-\mathrm{scF} \mathrm{V}_{\mathrm{TNT}}-\mathrm{EK}-\mathrm{EGFP}$ (a) (b) and three-insert Sil3 ${ }_{\mathrm{T} 8}$-Cy3TAG-scFv ${ }_{\mathrm{TNT}}$ (c) (d) Gateway expression clone (Table S4, lines 2 and 3, respectively) genomic integration screening by multiplex (a) (c) or single product (b) (d) PCR. PCR was performed on NATresistant T. pseudonana cell lines. (a) Lanes 1-6: PCR results from sample NAT-resistant cell lines; Lane 7: 2-log DNA size ladder (New England BioLabs). (b) Lanes 1-10: PCR results from sample NAT-resistant cell lines; Lane 11: 2-log DNA size ladder. (c) Lanes 1-8: PCR results from sample NAT-resistant cell lines; Lane 9: 2-log DNA size ladder. (d) Lanes 1-9: PCR results from sample NAT-resistant cell lines; Lane 10: plasmid control; Lane 11: 2-log DNA size ladder. Multiplex PCR indicated that while each component of the chimeric fusion construct was present in the T. pseudonana genome, the full-length fusion protein gene was not integrated continuously. The construct appears to have been linearized upstream of the EGFP sequence prior to integration. Note the presence of a faint band in (a) that likely corresponds to the $0.8 \mathrm{~kb}$ product from the $f c p$ promoter through the $\mathrm{TNT}_{\mathrm{scFv}}$. Redesign of the expression clone, to exclude EGFP, resulted in detection of full-length chimeric fusion gene integration events (d). Results for the $\mathrm{sdAb}_{\mathrm{EA} 1}$ series of clones were similar (data not shown). 


\section{a. RT-PCR for scFv $_{\mathrm{TNT}}$ expression}
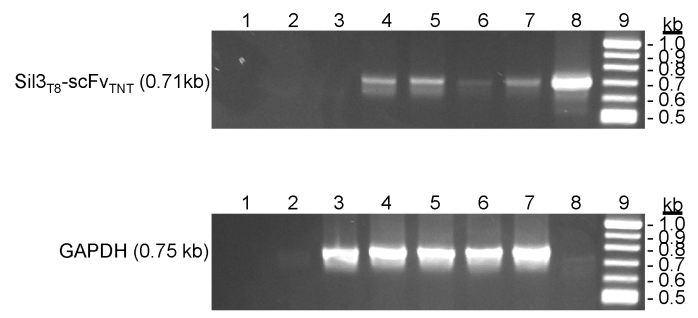

b. RT-PCR for $s d A b_{E A 1}$ expression
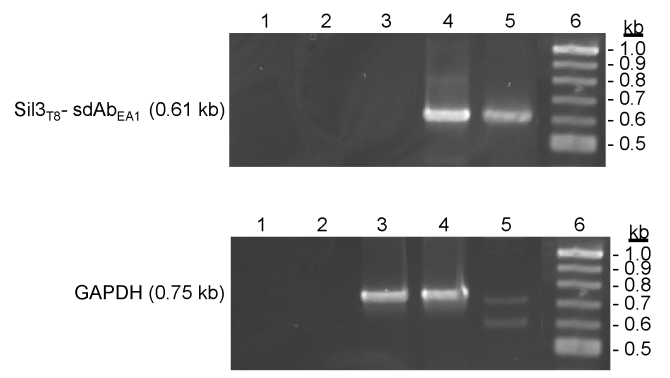

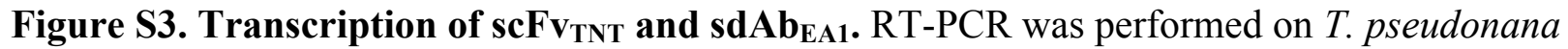
cells expressing either $\mathrm{Sil}_{\mathrm{T} 8}-\mathrm{Cy} 3 \mathrm{TAG}-\mathrm{scF}_{\mathrm{TNT}}$ (a) or $\mathrm{Sil}_{\mathrm{T} 8}$-Cy3TAG-sdAb ${ }_{\mathrm{EA} 1}$ (b). (a) Lane 1: non-templated control; Lane 2: no-reverse transcriptase control; Lane 3: native T. pseudonana; Lanes 4-7: NAT-resistant cell lines; Lane 8: plasmid control; Lane 9: 2-log DNA size ladder (New England BioLabs). (b) Lane 1: non-templated control; Lane 2: no-reverse transcriptase control; Lane 3: native T. pseudonana; Lane 4: NAT-resistant cell line; Lane 5: plasmid control; Lane 6: 2-log DNA size ladder. 


\section{(SEE ATTACHED MOVIE FILE)}

Figure S4. 3D-SIM movie of diatom expressing Sil3 ${ }_{\mathrm{T} 8}-\mathrm{Cy} 3 \mathrm{TAG}$-EGFP. T. pseudonana cells expressing Sil3 ${ }_{\text {T8 }}$-Cy3TAG-EGFP (green) were labeled with AsCy3e (red) and stained with PDMPO (blue). Additional colors emerged as a result of co-localization of the labels. 
a. Phase shift and modulation

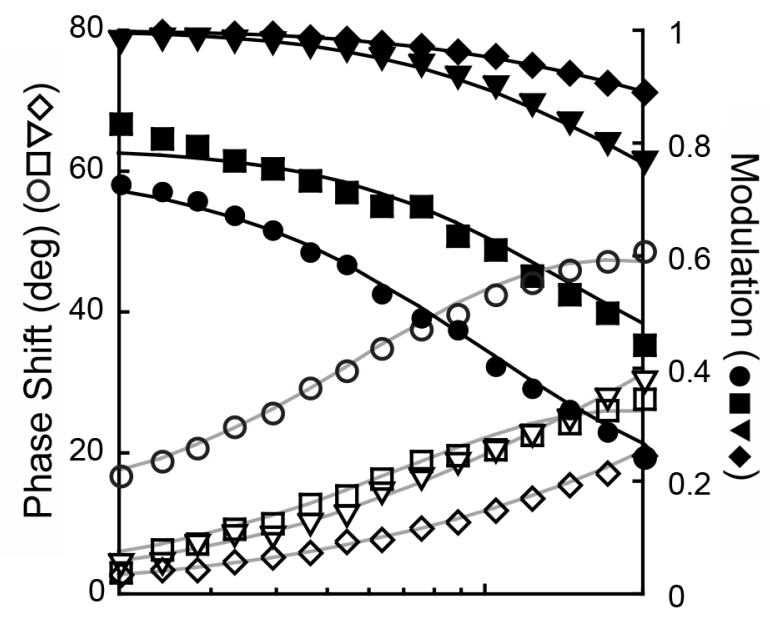

b. Weighted residuals

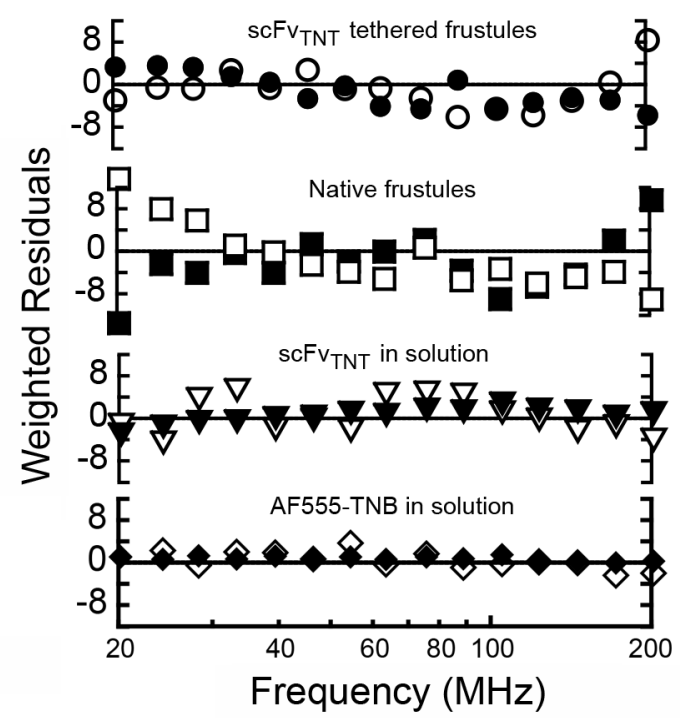

Figure S5. Frequency domain fluorescence microscopy of AF555-TNB bound to free and biosilica-immobilized scFv $\mathbf{v}_{\text {TNT }}$. a. Nonlinear least squared fits for phase shift (open symbols) and modulation (closed symbols); b. Weighted residuals; Experimental conditions were AF555TNB in solution (diamonds) or bound to purified $\mathrm{scFv}_{\mathrm{TNT}}$ in solution (triangles) and AF555-TNB bound to purified native (squares) or $\mathrm{scF}_{\mathrm{TNT}}$ tethered (circles) frustules $\left(10^{6} / \mathrm{mL}\right)$ isolated respectively from native or transformed diatoms. 
- SUPPLEMENTARY REFERENCES

[1] Poulsen, N., Chesley, P. M., and Kroger, N. (2006) Molecular genetic manipulation of the diatom Thalassiosira pseudonana (Bacillariophyceae), Journal of Phycology 42, 10591065.

[2] Poulsen, N., Berne, C., Spain, J., and Kroger, N. (2007) Silica immobilization of an enzyme through genetic engineering of the diatom Thalassiosira pseudonana, Angewandte Chemie-International Edition 46, 1843-1846.

[3] Poulsen, N., Scheffel, A., Sheppard, V. C., Chesley, P. M., and Kroger, N. (2013) Pentalysine Clusters Mediate Silica Targeting of Silaffins in Thalassiosira pseudonana, J. Biol. Chem. 288, 20100-20109.

[4] Scheffel, A., Poulsen, N., Shian, S., and Kroger, N. (2011) Nanopatterned protein microrings from a diatom that direct silica morphogenesis, Proc. Natl. Acad. Sci. U. S. A. 108, 3175-3180.

[5] Henegariu, O., Heerema, N. A., Dlouhy, S. R., Vance, G. H., and Vogt, P. H. (1997) Multiplex PCR: Critical parameters and step-by-step protocol, Biotechniques 23, 504-511.

[6] Hildebrand, M., and Dahlin, K. (2000) Nitrate transporter genes from the diatom Cylindrotheca fusiformis (Bacillariophyceae): mRNA levels controlled by nitrogen source and by the cell cycle, Journal of Phycology 36, 702-713.

[7] Davis, A. K., Hildebrand, M., and Palenik, B. (2006) Gene expression induced by copper stress in the diatom Thalassiosira pseudonana, Eukaryotic Cell 5, 1157-1168.

[8] McGinn, P. J., and Morel, F. M. M. (2008) Expression and regulation of carbonic anhydrases in the marine diatom Thalassiosira pseudonana and in natural phytoplankton assemblages from Great Bay, New Jersey, Physiologia Plantarum 133, 78-91.

[9] Liu, J. L., Zabetakis, D., Acevedo-Velez, G., Goldman, E. R., and Anderson, G. P. (2013) Comparison of an antibody and its recombinant derivative for the detection of the small molecule explosive 2,4,6-trinitrotoluene, Analytica Chimica Acta 759, 100-104.

[10] Walper, S. A., Anderson, G. P., Lee, P. A. B., Glaven, R. H., Liu, J. L., Bernstein, R. D., Zabetakis, D., Johnson, L., Czarnecki, J. M., and Goldman, E. R. (2012) Rugged Single Domain Antibody Detection Elements for Bacillus anthracis Spores and Vegetative Cells, Plos One 7. 